\title{
Assessing The Impact Of Wellness Programs Across Multiple Worksites: An Alternative To Return On Investment
}

Karen H. Larwin, Youngstown State University, USA

\begin{abstract}
The current case study looks at an innovative approach to assessing the impact of a large-scale workplace wellness program across seven different employer locations. Unlike many reports on the effectiveness of workplace wellness programs, this study does not use return on investment (ROI), which is limited in its ability to provide good estimates of insurance cost savings. The case study looks at a multi-year workplace wellness programs' impact on clinical measures from baseline through year two data collection. As a unique approach, meta-analytic results provide estimates that are both valid and reliable. Additionally, these measures are standardized, making them assessable for comparisons across different program implementations.
\end{abstract}

Keywords: Workplace Wellness Programs; Meta-Analysis; Return on Investment; Odds Ratio

\section{INTRODUCTION}

$\mathrm{n}$ response to the growing cost of healthcare, many corporations and organizations are embracing some form of workplace wellness programs (American Institute for Preventive Medicine, 2012), and in response to the growing popularity of these programs, an increasing number of reports have focused on whether these workplace wellness programs have an impact on participant's health and subsequently generate savings. A review of the literature indicates yes they do work, but not likely at the 3:1 rate of ROI that is commonly suggested (Mattke, Seid, \& Ma, 2007). What is unfortunate is that most of the large-scale population-based findings are based on numbers generated by the very insurance providers who are providing the programing (Fireman, Bartlett, \& Selby, 2004; Sidorov, Shull, Tomcavage, Girolami, Lawton, \& Harriss, 2002; Villagra \& Ahmed, 2004). These studies lack transparency and adherence to good scientific methods.

When examining wellness programs across different locations, the ability to generate any value of Return on Investment (ROI) with confidence becomes increasingly problematic. The challenges exist because each corporation/organization potentially purchases different insurance packages from different insurance providers in which each employee chooses from a menu of options. In addition, the employer groups likely have different numbers of employees that participate in the program activities. Research that has attempted to meta-analyze workplace wellness studies have developed their own decision rules and have come away with ROI estimates that are feeble at best (i.e., Chapman, 2008; Baicker, Cutler\& Song, 2010). These studies focus on one or two aspects of health (such as absenteeism data and/or productivity measures) which can be impacted by variables beyond the wellness programs being measured (Larwin \& Larwin, 2011). As a result, a group of meta-analytic studies synthesizing the results of workplace wellness programs in the U.S. from 1995-2005 conclude that the impact of these program result in a savings ranging from $\$ 1.47$ to $\$ 15.60$ per dollar spent (e.g.: Baicker, et al., 2010, Chapman, 2007; Goetzel et al., 2005; Lang, 2009; Mattke, et al. 2009, etc.). Conclusions from these studies generally reflect the conclusions of Lang (2009): "Healthcare costs - while important- are really only a small part of the overall ROI ... which can be attributed to a number of other factors"... many of which are not directly measureable." 
In spite of these less-than-ideal estimates, ROI continues to be the hallmark measure of the potential impact of wellness programing. The current case study suggests that ROI is not the best approach for measuring the impact of wellness programs when multiple locations or multiple studies are being meta-analyzed. The meta-analytic approaches being suggested can provide standardized measures on program impact. Meta-analysis can take two forms - one which uses primary data or raw data and another which uses summary or secondary data. An example of the former is a meta-analytic summary which compares primary data and synthesizes data across a number of contexts when raw data is available. With this type of meta-analysis, the researcher is "learning by comparing studies" through additional analysis in an effort to further explore the phenomena under study (Cooper \& Hedges, 2009 , p 18). The second type of meta-analysis is commonly referred to as a quantitative literature review, or research synthesis using secondary data (Cooper \& Hedges, 2009). In this type of meta-analytic study, the researcher uses the existing available research on a specific topic area in order to establish the overall strength of an effect, according to research that has already been conducted (Glass, McGaw, \& Smith, 1981). The current investigation is the first type of meta-analysis in that it uses raw data gathered from seven different employer locations. Data for the purpose of this reporting focuses on at risk versus not at risk measures on health conditions from baseline to year two measures.

\section{METHOD}

\section{Participants}

Participants for the current investigation include employees from seven different employee groups located within five miles of each other. These employer groups agreed to participate in the community-wide wellness initiative in a small mid-western town. For their participation, the employer groups were provided with funds to offset the cost of incentives (with these funds being provided by a local foundation). Employees at each organization were encouraged to participate in the wellness activities in exchange for lowered out-of pocket health care costs. Participation, however, was voluntary. Data were collected on a total of $n=789$ participants across the seven employer groups for the first two years of this multi-year program. The number of participants at each employer group ranged from as few as eight to as many as 279 .

\section{Instrumentation}

The reported values represent clinical data, including BMI, blood pressure, fasting lipid profiles consisting of triglyceride, total cholesterol, HDL, LDL and blood glucose data. These values were provided by a local health care organization that gathered the necessary information on an annual basis. The data were aggregated for each employer location and reported based on the number of individuals who were at risk or not at risk based on CDC standards (cdc.gov).

\section{Procedures}

Baseline data was gathered from all participants at the beginning of the program implementation and at the beginning of year two of program activities. Program activities were standardized across locations and included online and face-to-face mini-lessons on health issues, nutrition, and exercise. Standard biometric analyses were conducted on the data gathered from the participants and provided to the researcher. All data was recoded to reflect whether the participants were considered to be at risk or not based on their health risk assessment information. This data was analyzed using odds ratios. The odds ratio is a statistic used to assess the risk of a particular outcome if a certain exposure or treatment is present. The odds ratio is a relative measure telling us how much more likely it is that someone who is exposed to the factor under study will develop the outcome as compared to someone who is not exposed (Bland \& Altman, 2000). More specifically, the data analysis looked at pre and post frequency data for individuals who were at risk versus not at risk across the two data collection periods, as demonstrated in Table 1. 
Table 1: Odds Ratio Report Table Example

\begin{tabular}{|l|c|c|}
\hline & $f$ & $f$ \\
$($ at risk) & $f$ & $f$ (not at risk) \\
\hline Pre & & \\
\hline Post & & \\
\hline
\end{tabular}

The odds ratios produced were meta-analyzed using a fixed effects model which appropriately weights the data from each location according to the number of participants. According to Borenstein (2011), fixed effect models assume all data is functionally equivalent; otherwise random effects models should be used. Data gathered and analyzed by the same individuals across the two data collections and clinical analysis of the data were all performed by the same laboratory. All odds ratio and meta-analyzing was performed in Comprehensive MetaAnalysis, a software program dedicated to meta-analytic research.

\section{RESULTS}

The results provide two pieces of information - the impact measures on the clinical data for the seven locations and then the aggregate impact measures from the seven locations (treatment group) compared to a local industry in the same community who has had a corporate-wide wellness program in place for a decade (control group). All participants were examined annually on the following measures: BMI, BP, Cholesterol, Blood Sugar, LDL, HDL and Triglycerides. Frequency values indicated how many participants were at risk/ not at risk and metaanalyzed using these frequencies. The results indicate, overall, the impact of the wellness programs from baseline to year one - Odds Ratio $=1.288, \mathrm{p}<.001$. This indicates an overall positive significant impact for the seven locations. The results for each of the measures gathered are provided in Table 2.

Additionally, analysis was conducted to measure the impact of the wellness activities for the treatment group relative to the control group, indicating that there were no differences, $p=.097$. These results indicate that the impact of the new workplace wellness program was not statistically different from the impact of the longstanding workplace wellness program.

Table 2: Odd Ratio Of Change From Baseline To Year Two

\begin{tabular}{|l|c|c|}
\hline \multicolumn{1}{|c|}{ Clinical Measure } & Odds Ratio Treatment & Odds Ratio Control \\
\hline BMI & $1.599^{*}$ & $1.546^{*}$ \\
\hline BP & $1.361^{*}$ & 0.496 \\
\hline Cholesterol & $1.572^{*}$ & 0.742 \\
\hline Blood Sugar & $1.881^{*}$ & $1.024^{*}$ \\
\hline LDL & 0.735 & $1.030^{*}$ \\
\hline HDL & $1.153^{*}$ & .669 \\
\hline Triglycerides & 0.831 & \\
\hline
\end{tabular}

Note: * indicates a significant change from baseline to year two

\section{CONCLUSION}

According to Mattke, et al. (2007), a review of the impact of wellness programs nationally suggests that "to date, support for population-based workplace wellness is more an article of faith" than a reasoned conclusion grounded on well-researched fact" (p.4). They maintained that the data was predominantly derived from small highintensity programs focusing on high-risk patients that are typically run as part of a demonstration project by the providers at a single site.

Accordingly, the current investigation was a population-based program which included the data from participants from seven different employer locations in one small Mid-Western community. Unlike much of the research cited above, the current study relinquished the traditional approach of producing ROI estimates because each of the seven employer locations provided their employees with a variety of options of level healthcare programs from different insurance providers. To compare these using ROI would not provide a good estimate of anything occurring as a result of the program activities. 
In light of that, meta-analyzing odds ratios did provide an approach to standardized measure across the seven locations of the impact of the program. (Odds ratio values for each location can be provided upon request). The results indicate that, overall, the program is having an impact on participants, with significant improvement in BMI, BP, overall Cholesterol, Blood Sugar and HDL clinical measures. Noteworthy is the fact that the new workplace wellness program was not having a different impact from a well-established workplace wellness program in the same community across the same period of time. The measures produced via the meta-analytic techniques provide results that are both valid and reliable.

Meta-Analysis is one of the "most powerful tools in the evaluator's toolbox" (Werner Wittman, personal communication, November, 2010). Although many insurance vendors have reported successful and cost-saving results from highly controlled workplace wellness programs, the use of ROI is not always a valid or reliable measure of what is occurring as a result of program activities. This is certainly the case when the impact of workplace wellness plans are being compared across different locations.

The current case study brings light to the fact that ROI is not always a good measure of impact and metaanalytic techniques provide a viable alternative. Meta-analysis overcomes the problems associated with the different insurance providers, insurance program choices, different insurance costs (for families relative to individuals), as well as the complexity added when trying to compare the impact on employer groups with varying numbers of employees. In meta-analysis, the effect sizes that are calculated weight the individual groups by sample size (or the amount of information the study has to contribute to the overall data) by using the inverse variance for weighting. Also, while the effect size measure provided does not give a cost-estimate of savings, the effect size estimate provided indicates whether program efforts are paying off by demonstrating that universally accepted healthcare indicators are improving.

\section{AUTHOR INFORMATION}

Karen Larwin received her $\mathrm{PhD}$ in evaluation, measurement, and statistics in 2007, from Kent State University. She has been teaching statistics and quantitative methods to undergraduate and graduate students since 2006. She is currently the lead chair of the American Evaluation Association Quantitative Method: Theory and Design section, as well as an active member of the United States Consortium for the Advancement of Undergraduate Statistics Education. She has been involved in program evaluation for a number of different healthcare and wellness programs since 2009. She currently works at Youngstown State University as a member of the doctoral faculty for the department of Foundations, Research, Technology, and Leadership. Please send correspondence to Karen Larwin, Youngstown State University. E-mail: khlarwin@ysu.edu

\section{REFERENCES}

1. American Institute for Preventive Medicine (2012). Retrieved from http://www.healthylife.com/template.asp?pageID=80

2. Baicker, K., Cutler, D., \& Song, Z. (2010). Workplace wellness programs can generate savings. Health Affairs, 29(2), 1-8.

3. Bland, J.M. \& Altman, D.G. (2002).Validating scales and indices, BMJ, 324. 606-607.

4. Borenstein, M. (2007). Introduction to meta-analysis. Retrieved from http://www. Metaanalysis.com/downloads/meta\%20Analysis\%

5. Chapman, L.S. (2007) An analysis of Cost Effectiveness of Workplace Wellness.

6. Cooper, H. M., \& Hedges, L. V. (2009). Research synthesis as a scientific process. In H. Cooper, L.V. Hedges, \& J.C. Valentine (Eds.), Handbook of research synthesis and meta-analysis (pp. 1-18). New York: Russell Sage Publications.

7. Fireman B., Bartlett J., \& Selby J. (2004). Can disease management reduce health care costs by improving quality? Health Aff (Millwood). 23, 63-75.

8. Glass, G. V., McGaw, B., \& Smith, M. L. (1981). Meta-analysis in social research. London: Sage Publications.

9. Goetzel, R. Z., Ozminkowski, R. J., Pelletier, K. R., Metz, R. D., \& Chapman, L. S. (2007). Emerging trends in health and productivity management. America Journal of Health Promotion, 22(1), 1-7. 
10. Lang, R. (2009). Wellness Solutions, ROI Whitepaper. Retrieved from https://www.uscorporatewellness.com/wp/wp.../whitepaper.pdf

11. Larwin, K.H., Larwin, D.A., Dawson, D. (2011, November). The value of meta-analytic research when formulating an evaluation plan: Implications for Return on Investment in a federally funded wellness initiative. Paper presented at the annual meeting of the American Evaluation Association, Anaheim, CA.

12. Mattke, S., Seid, M., \& Ma, S. (2007). Evidence for the effect of disease management: is $\$ 1$ billion a year a good investment?. The American Journal of Managed Care, 13(12), 670-676.

13. Sidorov J., Shull R., Tomcavage J., Girolami S., Lawton N., \& Harris R. (2002). Does diabetes disease management save money and improve outcomes? A report of simultaneous short-term savings and quality improvement associated with a health maintenance organization-sponsored disease management program among patients fulfilling health employer data and information set criteria. Diabetes Care. 25, 684-689.

14. Villagra V.G., \& Ahmed T. (2004). Effectiveness of a disease management program for patients with diabetes. Health Aff (Millwood). 23,255-266. 


\section{NOTES}

